\title{
Rhabdophis tigrinus is not a pit viper but its bites result in venom-induced consumptive coagulopathy similar to many viper bites
}

\author{
Anjana Silva ${ }^{1 *}$, Toru Hifumi ${ }^{2 *}$, Atsushi Sakai ${ }^{3}$, Akihiko Yamamoto ${ }^{4}$, Masahiro Murakawa ${ }^{5}$, Manabu Ato ${ }^{6}$, \\ Keigo Shibayama ${ }^{4}$, Akihiko Ginnaga ${ }^{7}$, Hiroshi Kato ${ }^{8}$, Yuichi Koido ${ }^{8}$, Junichi Inoue ${ }^{9}$, Yuko Abe ${ }^{2}$, Kenya Kawakita ${ }^{2}$, \\ Masanobu Hagiike ${ }^{2}$ and Yasuhiro Kuroda ${ }^{2}$
}

\begin{abstract}
As a response to the recent article by Hifumi et al. published in the Journal of Intensive Care, the present correspondence clarifies the family-level taxonomy of the yamakagashi (Rhabdophis tigrinus). Further, the relevance of the term 'venom-induced consumptive coagulopathy,' instead of disseminated intravascular coagulation, in describing the procoagulant coagulopathy of $R$. tigrinus is highlighted.
\end{abstract}

Keywords: Viperidae, Colubridae, Natricinae, Rhabdophis, Coagulopathy

\section{Correspondence}

\section{Anjana Silva}

Dear Editor,

I read with interest, the research article titled 'Clinical characteristics of yamakagashi (Rhabdophis tigrinus) bites: a national survey in Japan, 2000-2013' by Hifumi et al. [1] published recently in the Journal of Intensive Care. Underreporting of snakebites has been a challenge in confronting the global burden of snakebite. Therefore, studies such as Hifumi et al. are with high value for the field of clinical toxinology as the authors have comprehensively described nine cases of $R$. tigrinus bites by providing clues for the pathophysiology of envenoming.

One major issue in the clinical reporting of snakebites is lack of emphasis on the taxonomic identity of the offending snakes, often leading to confusions [2]. Since the clinical reporting of snakebites is primarily done by the clinicians, this could be expected. In Hifumi et al. [1], $R$. tigrinus has been erroneously mentioned as a pit viper species (family: Viperidae, subfamily: Crotalinae). R. tigrinus has long been placed within the family Colubridae,

\footnotetext{
*Correspondence: nkanjanasilva@gmail.com; hifumitoru@gmail.com 'Department of Parasitology, Faculty of Medicine and Allied Sciences, Rajarata University of Sri Lanka, Anuradhapura, Saliyapura 50008, Sri Lanka 2Emergency Medical Center, Kagawa University Hospital, 1750-1 Ikenobe, Miki, Kita, Kagawa 761-0793, Japan

Full list of author information is available at the end of the article
}

under the subfamily Natricinae and genus Rhabdophis $[3,4]$, and therefore is not a pit viper but is a colubrid. Although some authors have suggested treating natricines as a separate family called Natricidae [5], recent molecular work confirmed the placement of natricines within the Colubridae as a subfamily [6]. All vipers (family: Viperidae) are venomous and possess front fangs. Pit vipers are an evolutionarily distinct group within the family Viperidae. As opposed to viperids, most of the snakes of the largest snake family Colubridae are non-venomous and do not possess true venom glands or venom delivery systems. Few mildly venomous snake groups within this family, such as the genus Rhabdophis, possess rear fangs as well as Duvernoy's glands which produce venom-like secretions and associated low-pressure venom delivery systems [7].

The pro-coagulant nature of $R$. tigrinus venom is primarily due to its prothrombin activating effects and weak thrombin-like effects. This leads to hypofibrinogenemia resulting hemorrhage in envenomed patients $[1,8]$. However, Hifumi et al. [1] described the above pathological process as the disseminated intravascular coagulation (DIC) with fibrinolytic phenotype. Interestingly, this pathological process has been described with the term 'venom-induced consumptive coagulopathy' (VICC) seen in many viperid snake groups (including many pit vipers) and Australian elapids. Although VICC is similar to DIC in many ways, VICC differs from the former by not usually 
resulting in end-organ effects, rapid onset and resolution, and the difference in the mechanism of initiation [9]. Hence, I suggest that the term VICC [9] is more suitable than DIC used by the authors to describe the coagulopathy due to $R$. tigrinus bites.

\section{Response}

Toru Hifumi, Atsushi Sakai, Akihiko Yamamoto, Masahiro Murakawa, Manabu Ato, Keigo Shibayama, Akihiko Ginnaga, Hiroshi Kato, Yuichi Koido, Junichi Inoue, Yuko Abe, Kenya Kawakita, Masanobu Hagiike, Yasuhiro Kuroda

\section{Dear Editor,}

We thank Dr. Silva for his comments on our article.

We completely agree that Rhabdophis tigrinus is a rear-fanged venomous snake present in paddy fields [10] and that its venom shows strong plasma coagulant activity, with prothrombin activating effects and weak thrombin-like effects that result in hemorrhagic symptoms [8]. Because $R$. tigrinus has no grooved fangs, envenomation does not occur in most bites; therefore, $R$. tigrinus has long been considered nonvenomous $[10,11]$.

However, we totally disagree with his suggestion that 'venom-induced consumptive coagulopathy' (VICC) is a more suitable term than 'disseminated intravascular coagulation' (DIC) with a fibrinolytic phenotype used to describe coagulopathy due to $R$. tigrinus bites.

First, we would like to provide the details of coagulation markers of case 5 in our previous studies [1,11]. A healthy 40-year-old man was admitted with severe coagulopathy that developed after $R$. tigrinus bites. On admission, he demonstrated significantly elevated levels of thrombin-antithrombin III complex (TAT, $60 \mathrm{ng} / \mathrm{mL}$; normal range, $<3-4 \mathrm{ng} / \mathrm{mL}$ ), plasmin-alpha 2-plasmin inhibitor complex (PIC, $22.3 \mu \mathrm{g} / \mathrm{mL}$; normal range, $<0.8$ $\mu \mathrm{g} / \mathrm{mL}$ ), and fibrinogen degradation products (FDPs, 592 $\mu \mathrm{g} / \mathrm{mL}$ ). He subsequently developed severe hypofibrinogenemia $(50 \mathrm{mg} / \mathrm{dL})$. Antivenom was administered $28 \mathrm{~h}$ after being bitten; after which, his hemorrhagic symptoms resolved. By day 3 of admission, scabs had formed over the bite wounds. Furthermore, his fibrinogen levels increased to $>100 \mathrm{mg} / \mathrm{dL}$, while his TAT, PIC, and FDP levels normalized. He was discharged on day 6 of admission. These coagulation markers fulfilled the diagnostic criteria for DIC with a fibrinolytic phenotype [12].

Second, Dr. Silva cited a research conducted by Isbister who suggested that a snakebite does not cause DIC but instead causes coagulopathy and thrombotic microangiopathy in snake envenoming; this was reportedly because VICC was not characterized by important features of DIC, such as evidence of systemic microthrombi and end-organ failure [9].

A similar discussion has been made in the context of trauma, which also induces DIC with a fibrinolytic phenotype in the acute phase. Rizoli et al. conducted a prospective study and concluded that within $24 \mathrm{~h}$ of trauma, most severely injured patients have DIC scores 'suggestive of' or of 'overt DIC' in the International Society on Thrombosis and Haemostasis (ISTH) score but have no anatomopathologic evidence of DIC. Considering that pathologic findings are the gold standard for diagnosis, then, DIC is exceptionally uncommon, and the ISTH score should not be used for trauma [13].

Asakura described important principals that enhanced fibrinolytic-type DIC (DIC with a fibrinolytic phenotype) is associated with marked activation of fibrinolysis corresponding to activation of coagulation. Fibrinolysis is strongly activated, hemostatic plugs (thrombi due to hemostasis) are more easily dissolved, and bleeding symptoms tend to be severe. However, organ dysfunction seldom occurs [12].

Therefore, it is obvious that we cannot find evidence of systemic microthrombi and that patients do not develop organ dysfunction in the phase of DIC with a fibrinolytic phenotype.

Third, the previous literature was limited by the sample size (nine cases) [1]; therefore, we are now preparing the next manuscript. We further analyzed 25 cases from the previous study [1]. Over the 43-year study period (19702013), 34 patients were identified, and the number of patients developing renal failure who required hemodialysis was significantly lower in the antivenom group than in the without-antivenom group ( $5.3 \%$ vs $40.0 \%, P=0.03)$. We assume that DIC with fibrinolysis phenotype does not persist throughout hospitalization and may be limited to the acute phase of injury for $R$. tigrinus bites. Renal failure requiring hemodialysis developed at a later phase of injury in $40 \%$ of patients not receiving antivenom. Examination of renal pathology revealed that glomerular fibrin thrombi and tubular necrosis were responsible for renal failure associated with $R$. tigrinus bites [14]. Indeed, Gando et al. reported that 24-48 h after severe traumatic injury, DIC with a fibrinolytic phenotype developed into that with a thrombotic phenotype, therefore resulting in fatal multiple organ dysfunction syndromes $[15,16]$.

In conclusion, we continue to assert that $R$. tigrinus bites induced DIC with a fibrinolytic phenotype.

\section{Competing interests}

The authors declare that they have no competing interests.

\section{Authors' contributions}

AnS wrote the correspondence. TH, AtS, AY, YA, and YK collected the patient data. TH, MM, MA, KS, AG, HK, YUK, J, YA, KK, and MH treated the patients.

$\mathrm{TH}$ wrote the manuscript. AY, AtS, and YaK revised and edited the manuscript. All authors read and approved the final manuscript.

\section{Author details}

${ }^{1}$ Department of Parasitology, Faculty of Medicine and Allied Sciences, Rajarata University of Sri Lanka, Anuradhapura, Saliyapura 50008, Sri Lanka. Emergency Medical Center, Kagawa University Hospital, 1750-1 Ikenobe, 
Miki, Kita, Kagawa 761-0793, Japan. ${ }^{3}$ The Japan Snake Institute, Yabutsuka 3318, Ota, Gumma 379-2301, Japan. ${ }^{4}$ Department of Bacteriology II, National Institute of Infectious Disease, Gakuen 4-7-1, Musashimurayama-shi, Tokyo 208-0011, Japan. ${ }^{5}$ Department of Internal Medicine, Kaizuka Hospital, Hakosaki 7-7-27, Higashi-ku, Fukuoka 812-0053, Japan. ${ }^{6}$ Department of Immunology, National Institute of Infectious Disease, Toyama 1-23-1, Shinjuku-ku, Tokyo 162-8640, Japan. ${ }^{7}$ The Chemo-Sero-Therapeutic Research Institute (KAKETSUKEN), 1-6-1 Okubo, Kita-ku, Kumamoto-shi, Kumamoto 860-8568, Japan. ${ }^{8}$ Division of Critical Care Medicine and Trauma, National Hospital Organization Disaster Medical Center, 3256 Midori-cho, Tachikawa, Tokyo 190-0014, Japan. ${ }^{9}$ Division of Critical Care Medicine and Trauma, Yamanashi Prefectural Central Hospital, 1-1-1 Fujimicho, Kofu, Yamanashi 400-8506, Japan.

Received: 8 June 2014 Accepted: 20 June 2014

Published: 31 July 2014

\section{References}

1. Hifumi T, Sakai A, Yamamoto A, Murakawa M, Ato M, Shibayama K, Ginnaga A, Kato H, Koido Y, Inoue J, Abe Y, Kawakita K, Hagiike M, Kuroda Y: Clinical characteristics of yamakagashi (Rhabdophis tigrinus) bites: a national survey in Japan, 2000-2013. J Intensive Care 2014, 2:19.

2. Wuster W, McCarthy CJ: Venomous snake systematics: implications for snake bite treatment and toxinology. In Envenomings and Their Treatments. Edited by Bon C, Goyffon M. Lyon: Foundation Marcel Merieux; 1996:13-23.

3. Ota H, Chen S, Lin J, Toriba M: Taxonomic status of the Taiwanese populations of Rhabdophis tigrinus (Squamata : Colubridae): morphological and karyological assessment. Japanese J Herpetol 1999, 18:1-6.

4. Takeuchi H, Ota H, Oh H, Hikida T: Extensive genetic divergence in the East Asian natricine snake, Rhabdophis tigrinus (Serpentes: Colubridae), with special reference to prominent geographical differentiation of the mitochondrial cytochrome b gene in Japanese populations. Biol J Linn Soc 2012, 105:395-408.

5. Vidal N, Delmas A-S, David P, Cruaud C, Couloux A, Hedges SB: The phylogeny and classification of caenophidian snakes inferred from seven nuclear protein-coding genes. C R Biol 2007, 330:182-187.

6. Pyron RA, Burbrink FT, Wiens JJ: A phylogeny and revised classification of Squamata, including 4161 species of lizards and snakes. BMC Evol Biol 2013, 13:93.

7. Weinstein SA, Warrell DA, White J, Keyler DE: Differences between buccal gland secretion and associated delivery systems of "true" venomous snakes and "colubrid" snakes: low- versus high-pressure gland function and canaliculated versus solid dentition. In "Venomous" Bites from NonVenomous Snakes: A Critical Analysis of Risk and Management of "Colubrid" Snake Bites. London: Elsevier; 2011:7-25.

8. Komori K, Konishi M, Maruta Y, Toriba M, Sakai A, Matsuda A, Hori T, Nakatani M, Minamino M, Akizawa T: Characterization of a novel metalloproteinase in Duvernoy's gland of Rhabdophis tigrinus tigrinus. J Toxicol Sci 2006, 31(2):157-168.

9. Isbister GK: Snakebite doesn't cause disseminated intravascular coagulation: coagulopathy and thrombotic microangiopathy in snake envenoming. Semin Thromb Hemost 2010, 36:444-451.

10. Morokuma K, Kobori N, Fukuda T, Uchida T, Sakai A, Toriba M, Ohkuma K, Nakai K, Kurata T, Takahashi M: Experimental manufacture of equine antivenom against yamakagashi (Rhabdophis tigrinus). Jpn J Infect Dis 2011, 64(5):397-402.

11. Hifumi T, Murakawa M, Sakai A, Ginnaga A, Yamamoto A, Kato H, Koido Y, Kawakita K, Hagiike M, Kuroda Y: A case of potentially fatal coagulopathy secondary to yamakagashi (Rhabdophis tigrinus) bites that completely recovered with antivenom administration. Acute Med Surg in press.

12. Asakura $\mathrm{H}$ : Classifying types of disseminated intravascular coagulation: clinical and animal models. J Intensive Care 2014, 2:20.

13. Rizoli S, Nascimento B Jr, Key N, Tien HC, Muraca S, Pinto R, Khalifa M, Plotkin A, Callum J: Disseminated intravascular coagulopathy in the first 24 hours after trauma: the association between ISTH score and anatomopathologic evidence. J Trauma 2011, 71 (5 Suppl 1):S441-S447.

14. Sakai A, Sawai Y: Study on the pathogenesis of envenomation by the Japanese colubrid snake, yamakagashi, Rhabdophis tigrinus. Snake 1990, 22:11-19.
15. Gando S, Sawamura A, Hayakawa M: Trauma, shock, and disseminated intravascular coagulation: lessons from the classical literature. Ann Surg 2011, 254(1):10-19.

16. Gando S: Acute coagulopathy of trauma shock and coagulopathy of trauma: a rebuttal. You are now going down the wrong path. J Trauma 2009, 67(2):381-383.

doi:10.1186/s40560-014-0043-6

Cite this article as: Silva et al:: Rhabdophis tigrinus is not a pit viper but its bites result in venom-induced consumptive coagulopathy similar to many viper bites. Journal of Intensive Care 2014 2:43.

\section{Submit your next manuscript to BioMed Central and take full advantage of:}

- Convenient online submission

- Thorough peer review

- No space constraints or color figure charges

- Immediate publication on acceptance

- Inclusion in PubMed, CAS, Scopus and Google Scholar

- Research which is freely available for redistribution

Submit your manuscript at www.biomedcentral.com/submit
C Biomed Central 